\title{
Analyses of an AC Linear Actuator for Cross-Wind Stabilisation and Rail Stress Reduction
}

\author{
Christoph Holtmann \\ Institute of Vehicle Concepts \\ German Aerospace Center \\ 70569 Stuttgart, Germany \\ Email: christoph.holtmann@dlr.de
}

\begin{abstract}
High-speed trains in light weight design require an actuator for cross-wind stabilisation. Also rail stresses due to heat generation by linear eddy current brakes (LECB) are still in discussion. This paper deals with the concept and design method of an AC linear actuator for cross-wind stabilisation and the reduction of rail heating. The linear actuator analysed in this work is first optimized for a maximum normal force for a given installation space and different pole pair numbers using an analytical approach. In a second step the brake force is analysed for different pole pair numbers with a harmonic 2-D-FEM analyses. To demonstrate the potential reduction of the rail temperature compared by using the linear eddy current brake of the ICE-3, a transient thermal 1-D-simulation of the rail head is done by using the heat generation rate of the harmonic 2-D-FEM analyses. The results show that the required normal force for cross-wind stabilization determined in the previous work can be achieved. With the constraints that two ICE-3 units passes the rail at maximum speed and braking force, the rail temperature can be reduced by $55^{\circ} \mathrm{C}$ compared to using the LECB of the high speed train ICE-3 of the German Railway (Deutsche Bahn).

Index Terms - eddy current brake, linear actuator, normal force, rail heating
\end{abstract}

\section{Introduction}

Side winds acting on vehicles is always a big safety issue [1]. Especially the lightweight design in double-deck configuration of the high speed train (HST) of the project Next Generation Train (NGT) of the German Aerospace Centre needs a special safety system to reduce the risk for a derailment. In [2] four different concepts for a cross-wind stabilisation system were discussed. The most promising concept is the use of an electromagnetic actuator which generates an attraction force to the rail. Foremost two concepts of such an actuator was analysed in [3]. The first concept of [3] is to apply an AC-current to the linear eddy current brake, which is used in the high speed train ICE-3 of the German Railway (Deutsche Bahn). With this concept an attraction force of ca. $9 \mathrm{kN}$ per meter can be reached and the $\mathrm{LECB}$ of the $\mathrm{ICE}-3$ can in principle be used for cross-wind stabilisation. A disadvantage of this concept is the higher order field harmonics which generates power losses in the rail even when the slip is zero. The relatively big higher order field harmonics are a result of the low number of grooves per pole and phase. Another concept in [3] is the use of an DC-current linear actuator.
The field of the DC-Linear actuator is constant along its length. Therefore if the linear actuator is infinitely long no braking force will be generated. With the DC-linear actuator a normal-force of $49 \mathrm{kN}$ per meter can be reached. As a result of end-effects of an DC-linear actuator with a finite length, a small braking force is always acting when the actuator is used for cross-wind stabilisation. The additional traction power to compensate this braking force at a speed of $20 \mathrm{~ms}^{-1}$ is about $8 \mathrm{~kW}$. However this actuator can not be used for braking applications.

A big problem with the use of the LECB of the ICE3 is the heat generation in the skin depth resulting in high surface temperatures and temperature gradients. The analyses in [8] came to the result of a maximum rail temperature rise of about $17^{\circ} \mathrm{C}$ by one pole pair at a speed of $380 \mathrm{~km} / \mathrm{h}$ which can be seen in figure 8 in [8] . In [8] the Rail temperature rise along the whole train was not analysed. So to get a better idea of this problem the previous task of this work was to calculate the rail temperature along the train length of the ICE-3 due to braking with the LECB. The approach for this calculation is also a part of this work (see section 5). As it can be seen in figure I.1 the rail temperature rises up to $120^{\circ} \mathrm{C}$ within one train unit of the ICE-3. Regarding two coupled

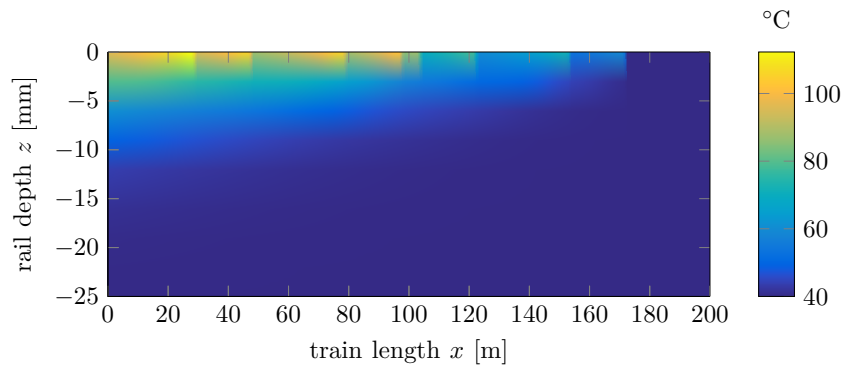

Fig. I.1: Result of a transient 1-D-simulation of the Temperature distribution in the rail along the train length of one train of the ICE-3. Because the simulation is done with constant velocity the time is proportional to the train length.

units of the ICE3 the temperature rises up to $140{ }^{\circ} \mathrm{C}$. With the assumption of an additional temperature rise of $20^{\circ} \mathrm{C}$ for every unit, the maximum Rail Temperature due 
to 4 following double unit trains will be approximately $260^{\circ} \mathrm{C}$. This temperature can already damage the rail due to heat treatment of the hardened rail head and due to heat stresses.

To reduce the rail heating, in the work of [5] an $\mathrm{AC}$ linear eddy current brake with ring windings is developed. The work shows that its possible to reduce the rail heating up to $60 \%$.

In this present work the theoretical analyses of a linear actuator will be shown which can be used for cross-wind stabilisation and the reduction of rail heating compared to the LECB of the ICE3.

\section{Concept of the Linear Actuator}

To use the linear actuator for cross-wind stabilisation and braking the possibility of a variable field excitation curve is a advantage. Because of the higher resistance of the eddy current path the eddy currents in the rail, in principle, will be lowest when the pole pair number is one. Therefore to reduce the losses in cross-wind stabilisation mode the linear actuator should be operated with an pole pair number of one. On the other hand, in braking mode the linear actuator should be operated such that the eddy currents in the rail get high as possible and/or the efficiency in braking energy recuperation mode gets highest. In braking mode there will be a optimal pole pair number which will not be one. In addition to increase the eddy current power, the air gap field should have high gradients at the pole edges. For this reasons a linear actuator with totally variable pole pair number and air gap field will be developed that can be operated in braking mode as well in cross-wind stabilisation mode.

A totally variable air gap field can be generated with ring windings shown in figure II.1 as used in [5]. In addition a linear actuator with ring windings has the highest potential to reduce the rail heating [5]. The question with which parameters such an actuator should operate in cross-wind stabilisation mode and in braking mode will be answered in this work.

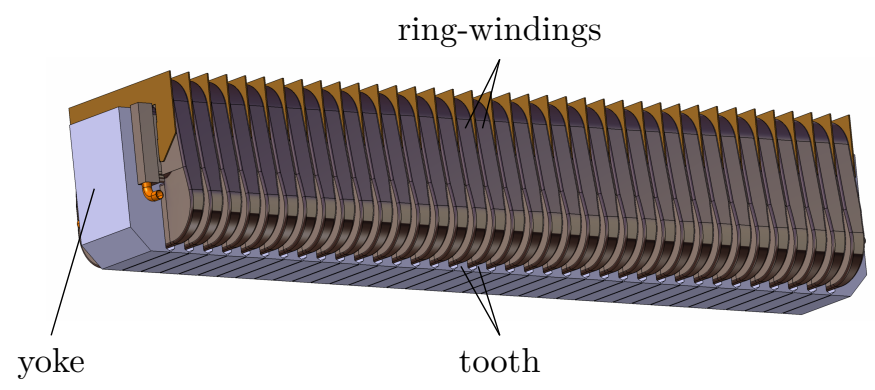

Fig. II.1: Linear actuator with ring windings

\section{Design Method and Input Parameters}

The linear actuator will be designed at first for a maximum normal force for cross-wind stabilisation. In a second step the brake force is analysed for different numbers of pole pairs. Initially it is assumed, that the optimal geometric parameters that result in an maximum normal force also result in a maximum braking force because both foremost depend on the amplitude of the air gap flux density. So the geometrical parameters will only optimized for a maximum normal force. The goal is to find the geometrical parameters listed in figure III.1. It has to be pointed out, that for a given length and height of the eddy current brake the only free parameters will be the pole number and the groove size corresponding to the height of the yoke $h_{j}$ and the width of tooth $b_{t}$. The width of the groove slot $b_{g s}$ depends of the wire diameter used for the windings and is therefore related to the flux linkage, voltage level and frequency. For a fast optimization process a lumped magnetic circuit and an analytical thermal model is used. During the optimization for every design point the maximum possible current density in the coils is calculated with the thermal model and applied to the lumped magnetic circuit.

The given geometrical parameters are shown in table III.1 and the material parameters in table III.2. For the yoke of the linear actuator the lamination M270-50a is used and the permeability of the rail is given in [3].

For the optimization it is convenient to define geometrical factors that can reaches values from zero to one. For the width of the tooth $b_{\mathrm{t}}$ and the height of the yoke $h_{\mathrm{y}}$ it is defined

$$
b_{\mathrm{t}}^{*}=\frac{b_{\mathrm{t}} N_{\mathrm{g}}}{l_{\mathrm{ecb}}} \quad \text { and } \quad h_{\mathrm{j}}^{*}=\frac{h_{\mathrm{y}}}{h_{\mathrm{ecb}}}
$$

TABLE III.1: Geometric input parameters for the optimization

\begin{tabular}{lccc}
\hline parameter & symbol & value & unit \\
\hline & & & \\
ECB length & $l_{\text {ecb }}$ & 0.63 & {$[\mathrm{~m}]$} \\
ECB height & $h_{\text {ecb }}$ & 0.16 & {$[\mathrm{~m}]$} \\
yoke depth & $b_{\mathrm{y}}$ & 0.07 & {$[\mathrm{~m}]$} \\
number of grooves & $N_{\mathrm{g}}$ & 32 & {$[-]$} \\
middle air gap width & $\delta_{\text {mid }}$ & 0.006 & {$[\mathrm{~m}]$} \\
\hline
\end{tabular}

TABLE III.2: Material parameters used for the optimization

\begin{tabular}{lccc}
\hline part/parameter & symbol & value & unit \\
\hline $\begin{array}{l}\text { copper wire } \\
\text { specific resistance }\end{array}$ & $\rho_{\text {cu20 }}$ & $0.0176 e-6$ & {$[\Omega \mathrm{m}]$} \\
temperature coeff. & $\alpha_{\mathrm{cu}}$ & 0.00381 & {$\left[\mathrm{~K}^{-1}\right]$} \\
$\begin{array}{l}\text { heat conductivity } \\
\text { winding impregnation }\end{array}$ & $\lambda_{\mathrm{cu}}$ & 385 & {$\left[\mathrm{~W} \mathrm{~m}^{-1} \mathrm{~K}^{-1}\right]$} \\
$\begin{array}{l}\text { heat conductivity } \\
\text { winding insulation paper }\end{array}$ & $\lambda_{\text {imp }}$ & 4.3 & {$\left[\mathrm{~W} \mathrm{~m}^{-1} \mathrm{~K}^{-1}\right]$} \\
$\begin{array}{l}\text { heat conductivity } \\
\text { thickness }\end{array}$ & $\lambda_{\text {ins }}$ & 1.2 & {$\left[\mathrm{~W} \mathrm{~m}^{-1} \mathrm{~K}^{-1}\right]$} \\
\hline
\end{tabular}




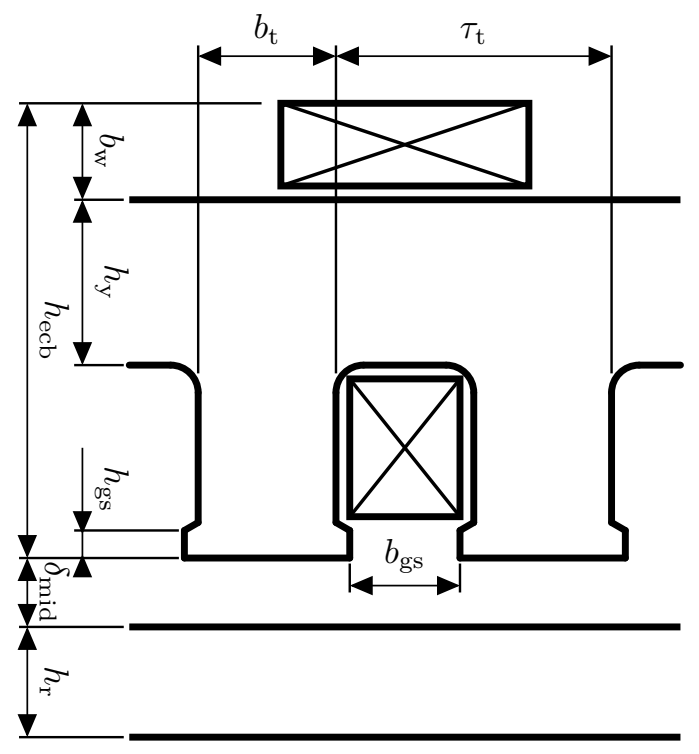

Fig. III.1: Geometrical parameters of the linear eddy current brake. The winding area in the groove and above the yoke are equal.

\section{Electromagnetic Model}

\section{A. Numerical Approach (eddy currents)}

The total magnetic field, the eddy currents in the rail and the resulting braking force only can be calculated with a FEM-Model by solving the form of Maxwell equations

$$
\begin{aligned}
& \nabla \times\left(\frac{1}{\mu_{0}} \nabla \times A-M\right)= \\
& =-\sigma\left(\frac{\partial A}{\partial t}-v \times \nabla \times A\right)+j_{\mathrm{e}}
\end{aligned}
$$

shown in [9], where $A$ is the vector potential $M$ the magnetisation, $\sigma$ the conductivity, $v$ the velocity and $j_{e}$ an externally applied current density. In this work equation (2) is solved with an harmonic approach. In actual fact, the harmonic FEM-calculations are done with zero velocity $v=0$ by applying a time harmonic current into the windings. The frequency of the time harmonic current causes a field wave moving with a relative velocity

$$
v_{\mathrm{fw}}=f 2 \tau_{p}
$$

Because the field wave is moving with the relative speed to the rail, the current induced by the relative speed can be calculated with the y component of the flux density in the rail $B_{y}$ and the velocity $v_{\text {rel }}$, corresponding to the second therm off the right side of equation (2).

$$
j_{\mathrm{v}}=\sigma_{\mathrm{reff}} v_{\mathrm{rel}} B_{y}
$$

The difference between the total eddy currents, as a result the harmonic calculation with zero train velocity and the relative velocity induced eddy currents are the eddy currents induced by a pulsating field component corresponding to the first therm at the right side of equation
(2). The pulsating eddy current component only depends on the speed of the excitation field wave relative to the moving reference frame, whereas the velocity induced eddy currents depend on the relative velocity of the field wave to the rail. In general the total eddy current for any given train speed, number of pole pairs and excitation frequency are the sum of the velocity induced eddy currents and the pulsating eddy currents. To approximate the eddy currents in the rail for every operating point $\left[v_{\text {rel }}, v\right]$ the total eddy currents are the sum of the velocity induced eddy currents as a function of the relative speed and the pulsating eddy currents as a function of the field velocity by using just the results of these two components of the harmonic analyses with $v=0$.

$$
j_{\text {tot }}=j_{\mathrm{v}}\left(v_{\text {rel }}\right)+j_{\text {puls }}\left(v_{\mathrm{fw}}\right)
$$

\section{B. Analytical Approach (normal force)}

In cross-wind stabilisation mode the eddy current brake is operated with zero slip and the eddy currents in the rail are negligible. So for a fast optimization process the air gap flux is calculated with a lumped magnetic circuit shown in figure IV.1 and the normal force is approximated with the Maxwell's traction force equation [7]. The total normal force of a linear eddy current brake with the number of tooth $N_{\mathrm{t}}=N_{\mathrm{g}}+1$ is approximately

$$
F_{\mathrm{n}}=\sum_{k=1}^{k=N_{\mathrm{t}}} \frac{A_{\mathrm{t}} B_{\delta k}^{2}}{2 \mu_{0}}=\sum_{k=1}^{k=N_{\mathrm{t}}} \frac{\phi_{\delta k}^{2}}{2 A_{\mathrm{t}} \mu_{0}}
$$

where $A_{t}$ is the cross section of the air gap related to one tooth, $B_{\delta k}$ is the normal flux density in the air gap of the tooth $k$ and $\phi_{\delta k}$ the magnetic flux in the air gap of the tooth $k$. The air gap flux is approximated with the reluctance model shown figure IV.1 as a result of the magnetomotive force $\theta_{\mathrm{g} k}$ in the grooves $k=1 \ldots k=N_{\mathrm{g}}$. The network of every groove $k$ results in four node and three mesh equations.

These equations results in a non linear equation system of the size $N_{\text {eqs }}=7 N_{\mathrm{g}}+4$ which is solved iteratively using the relative permeability's of the materials as a function of the flux density. The magnetomotive force $\theta_{\mathrm{g} k}$ of one groove $k$ is a result of the coil area $A_{\mathrm{cg}}$ and the current density $j_{k}(t)$.

$$
\theta_{\mathrm{g} k}=A_{\mathrm{cg}} j_{k}(t)=A_{\mathrm{cg}} \hat{j}_{1} \Re \sum_{n=1}^{n=N_{h}} i a_{n} e^{i n\left(2 \pi f t+\frac{\pi}{\tau_{p}} \tau_{t} k\right)}
$$

Where $\hat{j}_{1}$ is amplitude of the first harmonic $a_{n}$ are the normalized n-th harmonics, $f$ the frequency, $\tau_{\mathrm{p}}$ the pole pitch and $\tau_{t}$ the tooth pitch. With the total harmonic disturbance THD and the effective current density $j_{\text {eff }}$ the first harmonic is

$$
\hat{j}_{1}=\frac{\sqrt{2} j_{\text {eff }}}{\sqrt{1+\mathrm{THD}^{2}}}
$$

The maximum effective current density $j_{\text {effmax }}$ is calculated with a thermal model which is not part of this paper. 


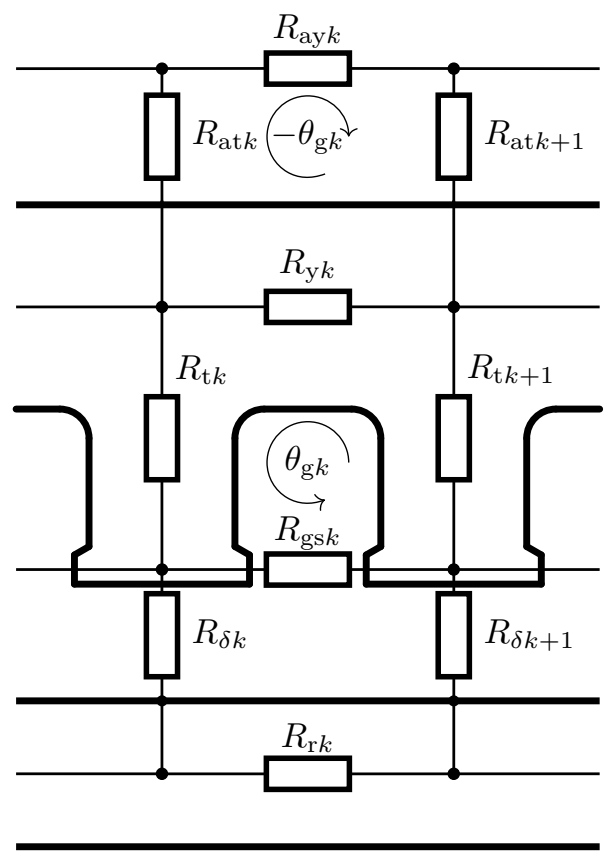

Fig. IV.1: Reluctance model related to one groove $k$ with the magnetomotive force $\theta_{\mathrm{g} k}$.

The verification of the reluctance model is done with a 2D-FEM model. Figure IV.2 show the normal component of the air-gap field as a result of the calculation via reluctance model and with the 2D-FEM model. The error of the resulting normal force of the reluctance model compared to the FEM model is less than $5 \%$.

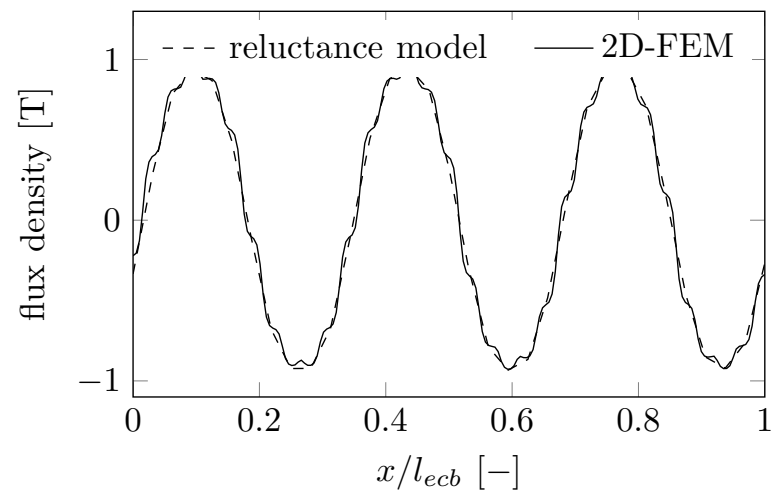

Fig. IV.2: Normal component of the air gap flux density calculated with the reluctance model and with the $2 \mathrm{~d}-$ FEM model.

The braking force is analysed solving equation (2) with a harmonic 2-D-FEM model by applying the complex magneto-motive force into the grooves. In a dc excited LECB the losses in the rail are exactly equal to the braking power generated by the eddy current brake

$$
F_{\mathrm{b}} v=\int_{V_{\text {railECB }}} \dot{q} \mathrm{~d} V=\int_{V_{\text {railECB }}} \rho_{\text {rail }} j_{\text {ec }}^{2}+\dot{q}_{\text {hyst }} \mathrm{d} V
$$

where $\rho_{\text {rail }}$ is the specific resistance of the rail, $j_{\text {ec }}$ the eddy current density and $\dot{q}_{\text {hyst }}$ heat generation rate due to hysteresis losses which are negligible. This is because the time derivative of the vector potential in equation (2) is zero in the moving reference frame and the electric field is only caused by the velocity $v$ of the moving conductor. By applying an ac current into the windings the time derivative of the vector potential is not zero and the losses in the rail will not be equal to the braking power.

\section{Thermal Rail Model}

The temperature distribution in the rail is approximated in a 1-D-simulation because the following assumption can be made:

- The heat generation rate in the rail, in lateral direction, is homogeneous distributed in the rail head (see figure 7 in [8] )

- The temperature gradient in moving direction $(x)$ is about 40 Kelvin per Meter

- The length of diffusion in the time of 3 seconds where one 200 meter train unit with maximum speed passes one rail element with a thermal diffusivity of $a=$ $1.6 e-5 m^{2} s^{-1}$ is

$$
x_{\text {diff }}=\sqrt{a t_{\text {brake }}}=0.0064 \mathrm{~m}
$$

which is just about $1 \%$ of the length of one eddy current brake

Further the simulation is done with adiabatic boundary conditions cause the heat transfer to the environment compared to the heat generation in the rail is negligible. The resulting middle heat generation rate due to the eddy currents under one eddy current brake as a function of the rail depth is

$$
\hat{\dot{q}}(z)=\frac{\rho_{\text {reff }}}{l_{\text {ecb }}} \int_{x=0}^{l_{\text {ecb }}} j_{\text {tot }}(x, z)^{2} \mathrm{~d} x
$$

- The time dependency of the heat generation rate is considered with the function $\chi(x(t))$ which describes the distribution of linear eddy current brakes along the train length. The function $\chi(x)$ is simply one where a actuator or eddy current brake is positioned above the rail and is zero where its not as illustrated in figure V.1. So the heat

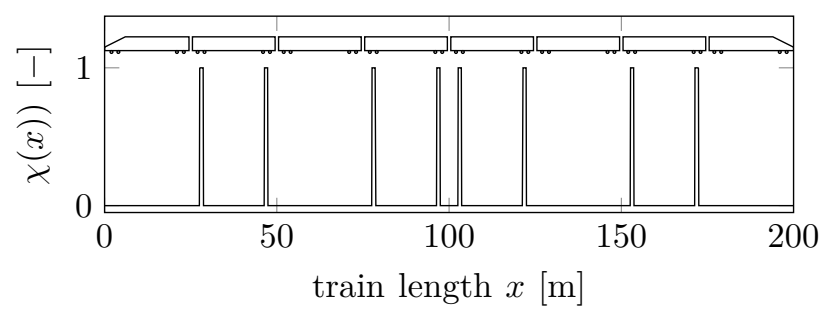

Fig. V.1: Distribution function for eddy current brakes or linear actuators along an ICE-3 train unit.

generation rate results in

$$
\dot{q}(z, t)=\chi(x(t)) \hat{\dot{q}}(z) .
$$


The temperature distribution in the rail by using the linear actuator is compared to those by using the LECB of the ICE-3. Because the eddy current distribution in the rail due to the LECB of the ICE-3 is not simulated in this work the eddy current distribtuion in the rail by using the LECB of the ICE-3 is approximated with

$$
j(z)=\hat{j} e^{\frac{z}{\delta_{\mathrm{s}}}} \quad \text { with } \quad \delta_{\mathrm{s}}=\sqrt{\frac{1}{\pi f \mu_{0} \mu_{r} \sigma}}
$$

where $\hat{j}$ is the current density at the rail surface, $\delta_{\mathrm{s}}$ the skin depth $z$ is the coordinate from surface of the rail head into the rail head and $f$ the frequency resulting from the train speed $v$ and pole width $\tau_{p}$. The current density at the rail surface can be calculated with the energy balance of the rail element under one eddy current brake generating the braking force $F_{e c b}$. The braking power in case of the LECB of the ICE-3 (dc-excitation) is

$$
P=F_{\text {ecb }} v=\rho_{\text {rail }} \int_{V_{\text {rail }}} j^{2} \mathrm{~d} V
$$

Combining equation (13) with (14) the volume specific heat generation under one LECB as a function of the rail depth $z$ is in case of the LECB of the ICE-3 approximately

$$
\hat{\dot{q}}(z)=\frac{F_{\mathrm{ecb}} v}{b_{\text {rail }} l_{\mathrm{ecb}} \delta\left(1-e^{-\frac{h}{\delta}}\right)} e^{\frac{z}{\delta}}
$$

By calculating the heat generation rate equation (11) or in case of the ICE-3 equation (15) and (12) the 1-D heat equation is solved with adiabatic boundary conditions with an initial temperature of $\vartheta(z, t=0)=\vartheta_{a m b}$ and a constant velocity.

\section{Results}

\section{A. Normalforce}

To find the optimal values for the yoke height and the tooth with, the normal force is optimized by varying $h_{y}^{*}$ and $b_{t}^{*}$ for $25 \times 25$ values. This is done for all relevant number of pole pairs $p=1 \ldots 4$. The maximum normal force will be reached with a pole pair number of $p=2$, a dimensionless yoke height of $h_{\mathrm{y}}^{*}=0.45$ and a dimensionless tooth width of $b_{\mathrm{t}}^{*}=0.75$. Figure VI.1 shows the normal force for maximum excitation current in the design space $\left[h_{\mathrm{y}}^{*}, b_{\mathrm{t}}^{*}\right]$ for a pole pair $p=2$. Against the assumptions the maximum normal force will be reached at a pole pair number of two instead of one. This is because the total height of the eddy current brake is relatively small. Also the optimal values in the design space $\left[h_{\mathrm{y}}^{*}, b_{\mathrm{t}}^{*}\right]$ are nearly equal for every pole number shown with the red squares in figure VI.1. Because the width of the tooth $b_{\mathrm{t}}^{*}=0.75$ results in a relatively small groove width where an integer number of wire has to be placed the width of the tooth is set to $b_{\mathrm{t}}^{*}=0.65$, resulting in a slightly lower normal force. However the requirement for the normal force as a result of [2] can be reached.

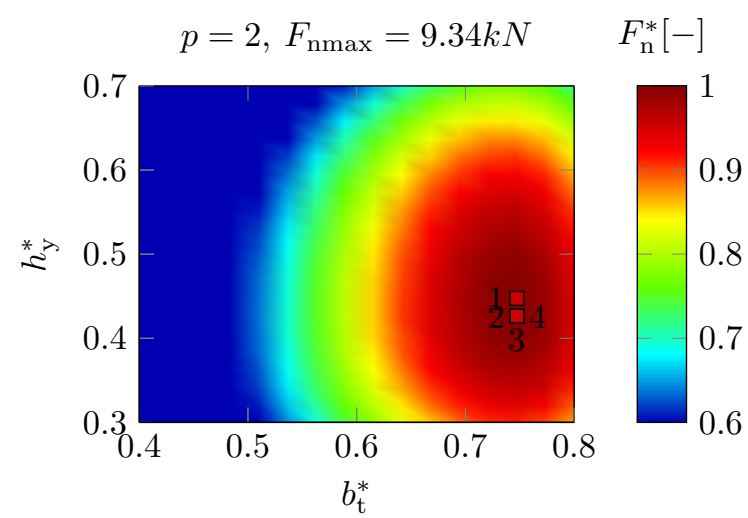

Fig. VI.1: Normal force in the parameter space $\left[b_{\mathrm{t}}, h_{\mathrm{y}}\right]$. The optimal values for the pole numbers $p=1, \ldots, 4$ are marked with the red markings.

\section{B. Brake Force and Rail Heating}

Figure VI.2 shows the braking force as a function of the relative velocity for different numbers of pole pairs $p$. The maximum braking force will be generated with a pole pair number of $p=2$ at a relative speed of $v_{\text {rel }}=10 \mathrm{~m} \mathrm{~s}^{-1}$. Figure VI.3 illustrates the resulting total eddy currents as the sum of the velocity induced eddy currents for a relative velocity of $v_{\text {rel }}=10 \mathrm{~ms}^{-1}$ where the brake force is at its maximum (see figure VI.2) and the pulsating eddy currents for a field speed of $v_{\mathrm{fw}}=-73,33 \mathrm{~ms}^{-1}$ corresponding to a train speed of $v=83.33 \mathrm{~m} \mathrm{~s}^{-1}$.

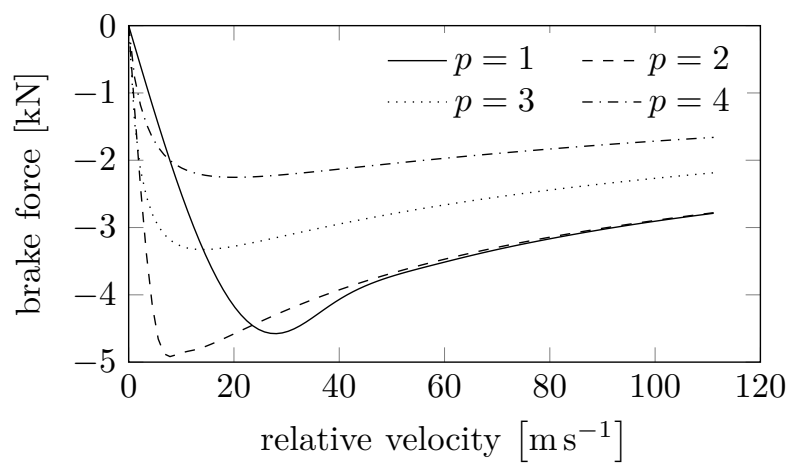

Fig. VI.2: Braking force of the actuator as a function of the relative velocity for $p=1, \ldots, 4$.

To compare the resulting rail temperature between the use of the LECB of the ICE-3 and the linear actuator, a 1-D-simulation of the heat transfer, with the constraints that two ICE-3 train units passes the rail at maximum speed and braking force, is done. Because the height of the linear actuator is smaller compared to the LECB of the ICE-3 the force per meter eddy current brake is less. So for the comparison the brake force of the ICE-3 is reduced by $23 \%$ to $77 \%$. Because of the approximation, in case of the ICE-3 different permeabilities are assumed for a sensitivity analyses. The resulting heat generation 


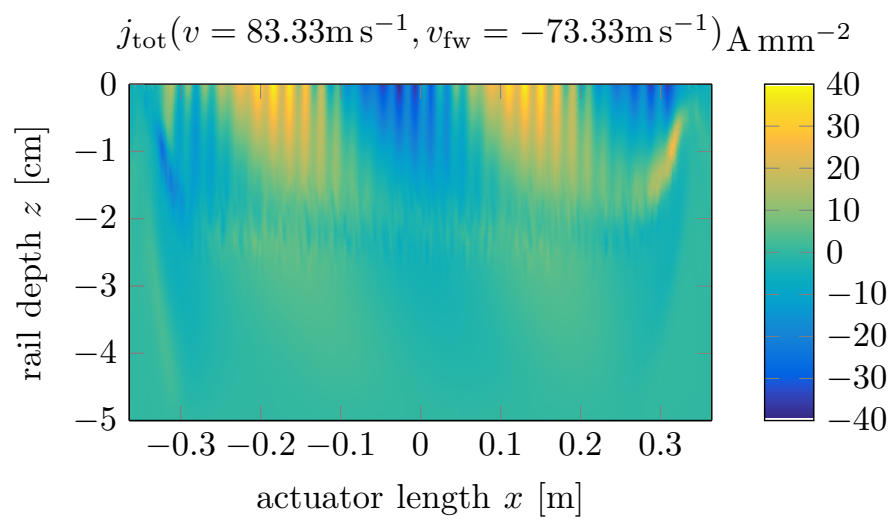

Fig. VI.3: Approximated resulting total eddy currents as the sum of the velocity induced eddy currents for a relative velocity of $v_{\text {rel }}=10 \mathrm{~m} \mathrm{~s}^{-1}$ and the pulsating eddy currents for a field speed of $v_{\mathrm{fw}}=-73,33 \mathrm{~m} \mathrm{~s}^{-1}$ corresponding to a train speed of $v=83.33 \mathrm{~m} \mathrm{~s}^{-1}$ as results of the harmonic 2-D-FEM analyses with $v=0$.

rate as function of the rail depth as a result of the eddy current distribution in figure VI.3 is shown with the solid line in figure VI.4. The dashed and dotted lines in figure VI.4 shows the heat generation rate in the rail by using the LECB of the ICE-3 with the assumption of a middle relative permeability of $\mu_{\mathrm{r}}=100$ and $\mu_{\mathrm{r}}=400$. It can be seen that the heat generation rate using the linear actuator within a few millimetres below the rail surface is about 1 to 2 magnitudes less compared to the use of the LECB of the ICE-3. Applying the heat generation rate

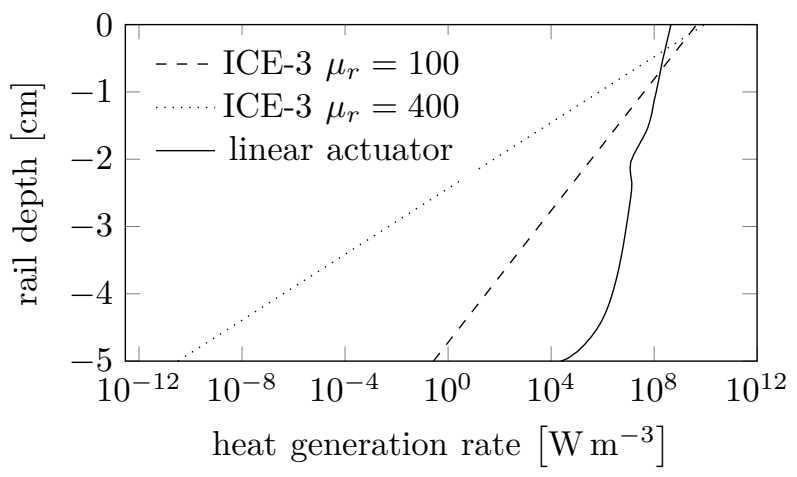

Fig. VI.4: Heat generation rate of the linear actuator (solid line) and by using the LECB of the ICE-3 with a assumed permeability of $\mu_{r}=100$ (dashed line) and $\mu_{r}=400$ (dotted line).

in a transient 1-D-Simulation to the rail, the rail surface temperature in figure VI.5 is the result. It can be seen that the surface temperature of the rail head can be reduced by $55{ }^{\circ} \mathrm{C}$ under the assumed constraints.

\section{Conclusion and Outlook}

This work shows the possibility to use a linear actuator for cross-wind stabilisation and braking. The required

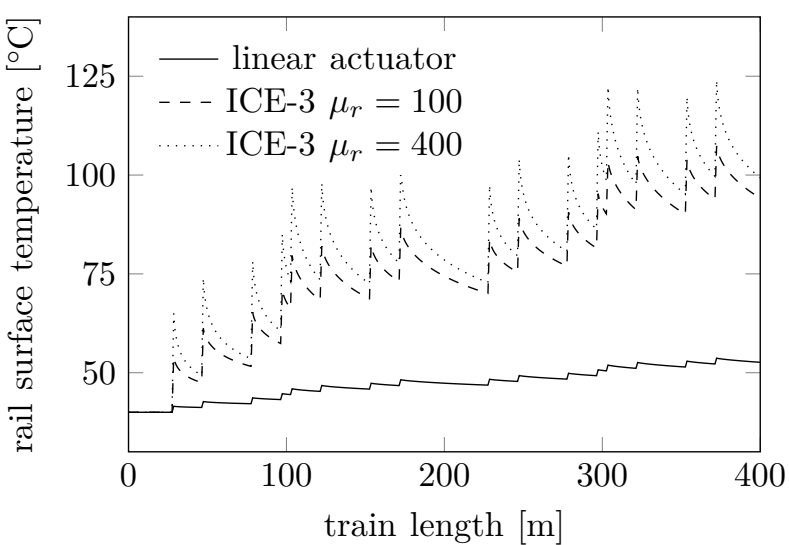

Fig. VI.5: Rail surface temperature under two 200 meter ICE3 train units as a result of a 1-D-Simulation of the linear actuator (solid line) and by using the LECB of the ICE-3 with a assumed permeability of $\mu_{r}=100$ (dashed line) and $\mu_{r}=400$ (dotted line).

normal force analysed in [2] can be achieved and the temperature of the rail surface can be reduced by about 55 ${ }^{\circ} \mathrm{C}$ compared by using the linear eddy current brake of the ICE-3 at the same braking force and train velocity. So far this work has shown that the results can be reached from electromagnetic and thermal view point of the actuator and of the rail. However the shown temperature reduction only can be achieved when the power electronics of each actuator is capable to transfer a power of about $400 \mathrm{~kW}$ into the intermediate high voltage circuit of the train grid. Therefore the focus in future will be the development of a power electronics for the linear actuator.

\section{References}

[1] Baker, Chris, et al. "Cross-wind effects on road and rail vehicles." Vehicle system dynamics 47.8 (2009): 983-1022.

[2] Heckmann, Andreas, et al. "Considerations on active control of crosswind stability of railway vehicles." Vehicle System Dynamics 52.6 (2014): 759-775.

[3] Werle, Thomas. Bemessung und Vergleich von Linear-Boostern für den Einsatz bei elektrischen Bahnen. Shaker, 2003.

[4] Lu, Xiaoshan, et al. "Rail temperature rise characteristics caused by linear eddy current brake of high-speed train." Journal of Traffic and Transportation Engineering (English Edition) 1.6 (2014): 448-456.

[5] KASHIWAGI, Takayuki, et al. "Basic Characteristics of Rail Brake Systems Using Linear Motor Technology." Quarterly Report of RTRI 50.3 (2009): 173-178.

[6] SAKAMOTO, Yasuaki, et al. "Performance of Linear Motor Type Rail Brake Using Roller Rig Test Bench." Quarterly Report of RTRI 53.1 (2012): 41-45.

[7] Kallenbach, Eberhard, et al. Elektromagnete: Grundlagen, Berechnung, Entwurf und Anwendung. Springer-Verlag, 2018.

[8] X. Lu, „Rail temperature rise characteristics caused by linear eddy current brake of high-speed train," Journal of Traffic and Transportation Engineering, Bd. 6, 2014.

[9] Zec, Mladen. Theory and numerical modelling of Lorentz force eddy current testing. Diss. 2013. 